\title{
Investigation of the influence of grain boundary on the magnetic and transport properties of superconducting ceramics $\mathrm{YBa}_{2} \mathrm{Cu}_{3} \mathrm{O}_{7-\delta}$

\author{
Rouver, A. N.; Passos, C. A. C. ${ }^{1}$; Orlando, M. T. D. ${ }^{1,2}$; Pinto, J. N. O.
}

1 Programa de Pós-Graduação em Engenharia Mecânica, Universidade Federal do Espírito Santo, Vitória, ES, Brasil 2 Programa de Pós-Graduação em Física, Universidade Federal do Espírito Santo, Vitória, ES, Brasil

\begin{abstract}
$\mathrm{YBa}_{2} \mathrm{Cu}_{3} \mathrm{O}_{7-\delta}$ polycrystalline ceramic samples were produced in order to study the thermal diffusivity. The samples were heat treated at different levels. These samples were characterized by XRD, ac magnetic susceptibility and scanning electron microscopy. The analyzes of the SEM image showed that the samples have different sizes of the junctions of grains. Samples A and B show $T c$ equal to $91.3 \mathrm{~K}$ and $91.3 \mathrm{~K}$, respectively. EDS analyzes indicated the concentration of ions in the center of the grain and edge grain for each sample. The measurements of thermal diffusivity, performed by flash method, indicated that the sample has a larger grain size, sample A, also has higher thermal diffusivity. Sample A also showed better magnetic shielding in the ac magnetic susceptibility measurements.
\end{abstract}

Keywords: supercondutor, YBaCuO, cerâmica.

\section{Introduction}

This study aimed to the experimental study of the effect of the size of the joints in the magnetic and transport properties in polycrystalline system $\mathrm{YBa}_{2} \mathrm{Cu}_{3} \mathrm{O}_{7-\delta}$.

\section{Sample preparation and synthesis}

Both samples used in this study were prepared by a solid state reaction by mixing $1 / 2 \mathrm{~mol}$ de $\mathrm{Y}_{2} \mathrm{O}_{3}, 2$ moles de $\mathrm{BaCO}_{3}$ e 3 moles de $\mathrm{CuO}$ in powder form in a agate mortar. samples were uniaxially compacted at a pressure of 1.00 ton. Different thermal treatments were used.

Table 1: Description of the homogenization heat treatment of superconducting samples.

\begin{tabular}{cccc}
\hline \multicolumn{4}{c}{ Heat Treatment } \\
\hline Sample & Temperature & Time & Cooling \\
A & $970^{\circ} \mathrm{C}$ & $24 \mathrm{~h}$ & $48^{\circ} \mathrm{C} / \mathrm{h}$ \\
B & $950^{\circ} \mathrm{C}$ & $24 \mathrm{~h}$ & $48^{\circ} \mathrm{C} / \mathrm{h}$ \\
\hline
\end{tabular}

\section{Characterization of samples}

\subsection{X-Ray Diffraction}

Phases identified for the samples $A$ and $B$ indicate that the main phase is $\mathrm{YBa}_{2} \mathrm{Cu}_{3} \mathrm{O}_{7-\delta}$.

\subsection{Magnetic Susceptibility}

The samples were subjected to measurement of ac magnetic susceptibility $(\chi a c)$.

The experimental apparatus is described for Passos [1].

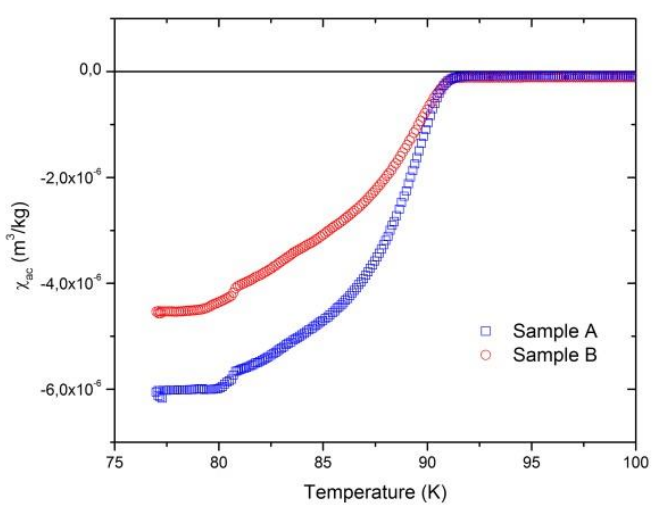

Figure 1: Measurement of ac susceptibility of the samples $A$ and $\mathrm{B}$ with magnetic field $\mathrm{H}_{\mathrm{a}}=5 \mathrm{~A} / \mathrm{m}$ and $v=4,23 \mathrm{kHz}$.

Measurements of $T_{c}$ at ambient pressure for each sample are shown in Table 2.

Table 2: $T_{c}$ values obtained for samples $A$ and $B$.

\begin{tabular}{cc}
\hline Sample & $\mathbf{T}_{\mathbf{c}}(\mathbf{K})$ \\
\hline A & 91,3 \\
B & 91,8 \\
\hline
\end{tabular}

The difference in the magnetic shielding which at $77 \mathrm{~K}$ may be related to the grain size of each sample.

\subsection{Scanning Electron Microscopy (SEM)}

The micrographs taken from the secondary electron signal (SE - secondary electron) are arranged in Figures 2 and 3. 


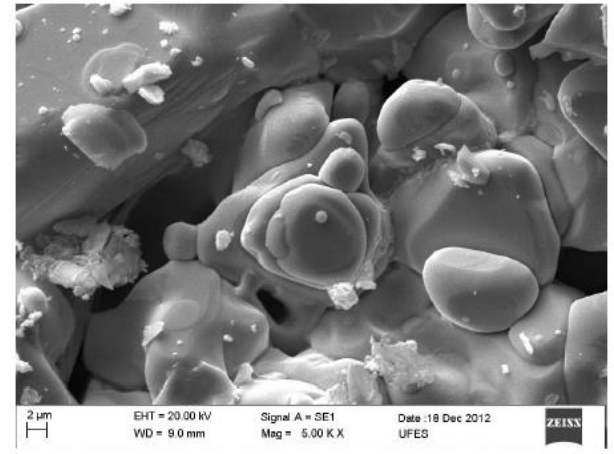

Figure 2: Image micrograph of sample A.

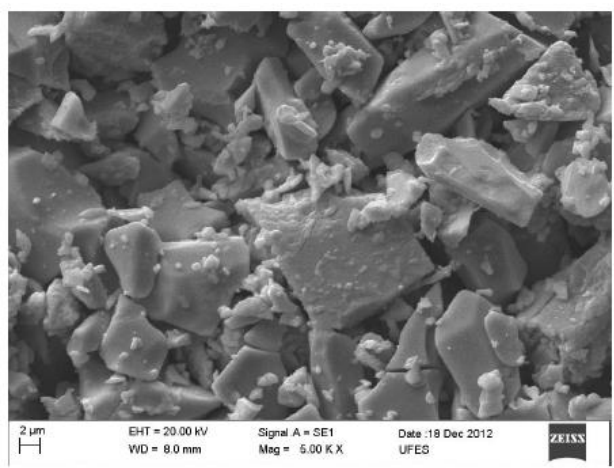

Figure 3: Image micrograph of sample B.

\subsection{Average Size of Junctions}

A quantitative analysis of the average grain size of the junctions was performed, based on the SEM images, with the aid of a density function of gamma distribution [2].

$$
f(x)=\left\{\begin{aligned}
\frac{\lambda^{\eta}}{\Gamma(\eta)} x^{\eta-1} \exp (-\lambda x), & \text { if } x \geq 0 \\
0, & \text { otherwise }
\end{aligned}\right.
$$

Parameters $\eta$ and $\lambda$ can be used to calculate the mean of the distribution $\mu$. Measures of the various line segments characterizing a junction between two or more grains were made. The results were arranged in histograms and analyzed to obtain the parameters $\eta$ e $\lambda$ adjusted to the histogram data [3].

Table 3: Parameters of the distribution and the values of the average sizes of $\mu$ junctions with their uncertainties.

\begin{tabular}{cccc}
\hline Sample & $\boldsymbol{\eta}$ & $\boldsymbol{\lambda}$ & $\boldsymbol{\mu}(\boldsymbol{\mu m})$ \\
\hline A & 4,22 & 0,74 & $5,72 \pm 0,06$ \\
B & 3,30 & 2,22 & $1,48 \pm 0,02$ \\
\hline
\end{tabular}

According to the data shown in Table 3, the average grain size of sample $A$ is larger.

\subsection{Thermal Diffusivity}

Flash method was used to obtain the thermal diffusivity [4], the experimental arrangement used to measure the thermal diffusivity is displayed in Figure 4.

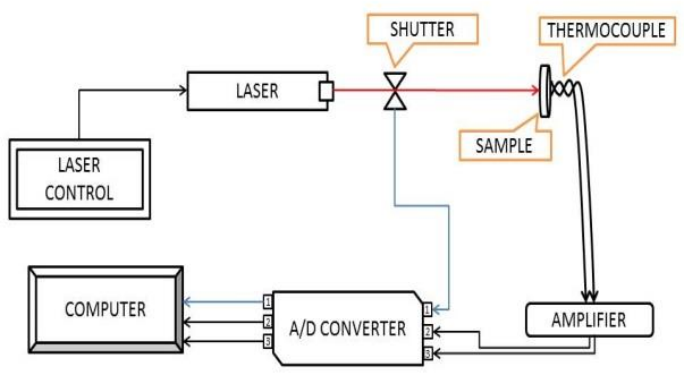

Figure 4: Experimental arrangement used to measure the diffusivity of the samples of YBaCuO.

A series of measurements of thermal diffusivity for samples A and B was performed, and the values that are presented in Table 4 are composed of the mean of each sample.

Table 4: Comparison between values of average size of $\mu$ junctions diffusivity $\alpha$.

\begin{tabular}{ccc}
\hline Sample & $\boldsymbol{\mu}(\boldsymbol{\mu m})$ & $\boldsymbol{\alpha}\left(\mathbf{c m} / \mathbf{s}^{\mathbf{2}}\right) \times \mathbf{1 0}^{-\mathbf{4}}$ \\
\hline A & $5,72 \pm 0,06$ & $8,4 \pm 0,6$ \\
B & $1,48 \pm 0,02$ & $7,1 \pm 0,6$ \\
\hline
\end{tabular}

\section{Conclusions}

A statistical analysis of SEM's showed that the sample A has a larger average size of the joints. Sample A also showed a higher thermal diffusivity than sample $B$, which means that it has less resistance to the transport of thermal energy and thus higher magnetic shielding found in the ac magnetic susceptibility measurements.

\section{Acknowledgements}

The authors thank FAPES, CNPq and CAPES for financial support.

\section{References}

[1] PASSOS, C. A. C. Investigação do diagrama de fases do supercondutor ( $\mathrm{Hg}, \mathrm{Re})-1223$ através de medidas de transporte. Vitória: Tese (Doutorado em Física), 2007. 161 p.

[2] ISO et al. Guia para a expressão da incerteza de medição. 3. ed. Rio de Janeiro: ABNT, INMETRO, 2003. $131 \mathrm{p}$.

[3] ROUVER, A. N. Determinação da influência do contorno de grão na medida de difusividade térmica em cerâmicas supercondutoras $Y$ Ba2Cu307- $\delta$. Vítoria: Dissertação (Mestrado em Engenharia Mecânica), 2013. 95 p.

[4] PARKER, W. J. et al. Journal of Applied Physics, v. 32, n. 9, p. 1679, 1961. 